\title{
Kemampuan Pemecahan Masalah Matematika Siswa Sekolah Dasar dengan Gaya Kognitif Field Dependent
}

\author{
Luluk Wahyu Nengsih ${ }^{1}$, Susiswo ${ }^{2}$, Cholis Sa'dijah $^{2}$ \\ ${ }^{1}$ Pendidikan Dasar-Universitas Negeri Malang \\ ${ }^{2}$ Pendidikan Matematika-Universitas Negeri Malang
}

\begin{tabular}{l}
\hline \hline INFO ARTIKEL \\
\hline Riwayat Artikel: \\
Diterima: 23-01-2019 \\
Disetujui: 11-02-2019 \\
\hline
\end{tabular}

\section{Kata kunci:}

mathematical problem solving; cognitive style; pemecahan masalah matematika; gaya kognitif; field dependent

\begin{abstract}
ABSTRAK
Abstract: This research is a descriptive qualitative study that aims to describe the profile of students' mathematical problem solving abilities with field dependent cognitive styles. The research subjects were fourth grade students of Islamic Elementary School Mohammad Hatta in Malang City. The study began by giving cognitive style tests, then continued with tests of mathematical problem solving and interviews. The validity of the data using triangulation and analyzing techniques used are data reduction, data exposure, and conclusion. The results of this study indicate that the problem solving steps at S1 tend to be in accordance with the Polya stage, while S2 and S3 tend to be inappropriate because there are several steps that are skipped over.
\end{abstract}

\begin{abstract}
Abstrak: Tujuan penelitian ini yaitu untuk mendeskripsikan profil kemampuan pemecahan masalah matematika yang dimiliki siswa field dependent sehingga termasuk pada jenis penelitian deskriptif kualitatif. Subjek penelitian ialah siswa kelas IV SD Islam Mohammad Hatta Kota Malang. Penelitian dimulai dengan memberikan tes gaya kognitif, kemudian dilanjutkan dengan memberikan tes pemecahan masalah matematika serta wawancara. Keabsahan data menggunakan triangulasi dan teknik analisis yang digunakan berupa reduksi data, pemaparan data, dan penarikan kesimpulan. Hasil penelitian ini menunjukkan bahwa langkah-langkah penyelesaian masalah pada S1 cenderung sesuai dengan tahapan Polya, sedangkan untuk S2 dan S3 cenderung tidak sesuai karena ada beberapa tahapan yang dilompati.
\end{abstract}

\author{
Alamat Korespondensi: \\ Luluk Wahyu Nengsih \\ Pendidikan Dasar \\ Universitas Negeri Malang \\ Jalan Semarang 5 Malang \\ E-mail: lulukwahyunengsih25@gmail.com
}

Setiap individu tentunya tidak pernah terlepas dari masalah dalam kehidupan sehari-hari. Masalah tersebut dapat berupa eksternal maupun internal yang memerlukan solusi penyelesaian dengan baik. Sebagai pelajar tentunya siswa sering mengalami masalah seperti dalam belajar matematika. Oleh sebab itu, maka menjadi penting bagi siswa menguasai matematika guna mengembangkan pengetahuan dan teknologi. Pernyataan ini diperkuat dengan dijadikannya matematika sebagai mata pelajaran wajib di setiap jenjang pendidikan. Namun, pada kenyataannya pembelajaran matematika di sekolah tampak sebagai kegiatan monoton. Pernyataan ini sejalan dengan Zaif, Sunardi, \& Diah (2013) yaitu suatu kegiatan yang procedural dan cenderung monoton merupakan ciri pembelajaran matematika sekolah saat ini. Guru hanya berperan untuk mejelaskan materi, memberi contoh, memberi tugas, mengecek jawaban secara sepintas, kemudian membahas dan siswa mencontoh, sedangkan proses berpikir siswa sesungguhnya yang menjadi esensi dari pembelajaran seolah terabaikan. Akibatnya konsep matematika kurang dipahami dengan baik oleh siswa sehingga berdampak pada hasil belajar yang diperoleh. Dengan demikian, seharusnya pembelajaran matematika di kelas lebih difokuskan untuk menumbuhkembangkan kemampuan berpikir siswa.

Kemampuan berpikir siswa dapat ditumbuhkembangkan salah satunya melalui pemecahan masalah. Dengan pemecahan masalah seseorang akan dituntut untuk berpikir secara sistematis, kritis, logis, serta memiliki sikap pantang menyerah untuk menemukan solusi dari masalah yang dihadapi. Anderson (2009) mendefinisikan pemecahan masalah sebagai suatu keterampilan individu dalam menganalisis, menafsirkan, menalar, memprediksi, mengevaluasi, dan merefleksikan. Sementara menurut Maimunah, Purwanto, Sa'dijah, \& Sisworo (2016) pemecahan masalah ialah aktivitas intelektual guna menemukan solusi penyelesaian dari masalah dengan melibatkan pengetahuan dan pengalaman. Lebih lanjut, Ulya (2016) menyatakan pemecahan masalah sebagai suatu kemampuan dalam mempergunakan pengetahuan yang sebelumnya telah diketahui pada situasi baru untuk menyelesaikan masalah. Dengan memecahkan masalah, maka siswa akan berusaha menemukan solusi yang tepat menurut caranya sendiri guna menyelesaikan masalah tersebut. 
Suherman (2003) mengatakan bahwa pemecahan masalah harus dikembangkan pada situasi yang bersifat ilmiah bertemakan kejadian dalam kehidupan sehari-hari atau yang menarik perhatian anak. Dengan kata lain, pemecahan masalah yang dihadirkan harus bersifat kontekstual yang nyata dan dekat dengan kehidupan anak. Salah satu jenis masalah yang kontekstual dapat berupa masalah non rutin yang memerlukan proses berpikir tingkat tinggi dalam penyelesaiannya.

Polya (1973) menjelaskan beberapa tahapan yang harus dilalui dalam menyelesaikan suatu masalah, antata lain (1) Memahami masalah, yaitu kemampuan siswa untuk menyebutkan apa yang diketahui, ditanyakan, dan dipersyaratkan; (2) Merencanakan strategi penyelesaian, yaitu siswa mampu mencari hubungan antara informasi-informasi yang diperoleh dengan pengalaman masa lampau. Kemampuan ini akan menuntun siswa untuk menyusun langkah-langkah penyelesaian; (3) Melaksanakan penyelesaian, yaitu siswa dapat menyelesaikan masalah berdasarkan rencana penyelesaian yang telah dibuat; (4) memeriksa kembali hasil berdasarkan tahapan yang ada, yakni kesediaan siswa untuk memeriksa kembali langkah yang telah ditempuh hingga menemukan hasil yang diharapkan. Siswa harus memiliki alasan yang tepat dan keyakinan bahwa jawaban yang diberikan benar. Selain itu, kegiatan memeriksa kembali dapat meminimalisir kesalahan yang mungkin terjadi. Hal inilah yang dijadikan sebagai indikator pemecahan masalah dalam penelitian ini.

Setiap individu memiliki perbedaan dalam proses memecahkan suatu masalah. Perbedaan tersebut antara lain terdapat pada intelegensi, kreativitas, sikap, minat, kemampuan berpikir, dan juga gaya kognitif. Dari beberapa faktor internal tersebut, salah satu yang menjadi perhatian dalam dunia pendidikan ialah gaya kognitif. Hal ini dikarenakan gaya kognitif berhubungan dengan kemampuan individu dalam menerima, menyimpan, mengorganisasikan, dan mengolah informasi. Pernyataan ini sejalan dengan Brown, Brailsford, Fisher, Moore, \& Ashman (2006) yang menyatakan bahwa gaya kognitif merujuk pada karakteristik individu untuk memahami, memproses, menyimpan, memikirkan, serta menerapkan informasi yang telah diperoleh dalam berbagai situasi dan kondisi. Slameto (Diana, Irawan, \& Susiswo, 2017) menyatakan bahwa gaya kognitif ialah cara yang digunakan individu untuk menyusun, memproses informasi serta pengalaman. Gaya kognitif setiap individu berbeda satu dan lainnya. Sejalan dengan itu, Desmita (2009) menyebutkan gaya kognitif menempati posisi penting dalam pembelajaran dan memengaruhi siswa dalam bidang akademik.

Pembelajaran matematika sangat erat berkaitan dengan gaya kognitif. Hal ini dikarenakan dalam kegiatan belajar siswa harus mampu mengolah informasi secara sistematis. Terdapat banyak dimensi gaya kognitif, salah satunya yaitu field independent dan field dependent (Salameh, 2011). Witkin, Moore, Goodeenough, \& Cox (1977) menyatakan siswa field independent memiliki sifat analitis dan sintesis dalam memahami masalah. Siswa mampu mengabstraksi elemen-elemen menjadi bagian yang lebih kecil dan lebih mandiri. Sedangkan siswa field dependent lebih condong untuk menerima apa adanya informasi. Sehingga siswa sangat bergantung pada lingkungan dalam mengorganisasi dan memproses informasi. Dalam penelitian ini lebih difokuskan kepada siswa field dependent.

Seseorang dengan field dependent lebih menggunakan pendekatan pengataman dalam belajaranya. Selain itu, menurut Witkin et al (1977) siswa dengan FD lebih berpikir secara global, berorientasi secara interpersonal, dan sensitif terhadap lingkungan sosial. Sehingga tidak mengherankan FD lebih tertarik untuk mengamati kerangka sosial, tertarik pada pesan-pesan secara verbal dalam konten sosial, serta lebih membutuhkan motivasi dan dorongan secara eksternal. Lebih lanjut, dalam keseharian FD merupakan pribadi yang hangat, mudah bergaul, responsif, dan juga ramah.

\section{METODE}

Penelitian berjenis deskriptif kualitatif ini bertujuan untuk mendeskripsikan kemampuan pemecahan masalah matematika siswa field dependent. Keabsahan data pada digunakan ialah kredibilitas dengan teknik triangulasi data, sedangkan dependabilitas dilakukan melalui dokumentasi terhadap semua kegiatan peneltian yang disusun secara runtut. Subjek penelitian ini ialah siswa kelas IV SD Islam Mohammad Hatta Kota Malang yang berjumlah tiga orang. Tahap pertama penelitian yaitu dengan memberikan tes gaya kognitif melalui instrumen berupa soal group embedded figure test (GEFT) yang dikembangkan oleh Witkin (1971). Adapun tujuan pemberian tes ini yaitu untuk mengetahui jenis gaya kognitif yang dimiliki siswa. Terhadap hasil jawaban siswa yang bernilai benar akan diberi skor 1 dan skor 0 untuk jawaban salah. Selanjutnya, total perolehan skor siswa kemudian dikelompokkan berdasarkan kriteria yang telah ditetapkan Gordon \& Wyant (1994) yakni skor 0-11 termasuk kategori field dependent dan skor 12-18 termasuk kelompok field independent. Tahap kedua yaitu pemberian tes pemecahan masalah kepada siswa yang terpilih sebagai subjek penelitian. Langkah terakhir yaitu dilakukannya wawancara dengan tujuan untuk mengonfirmasi jawaban yang diberikan siswa.

Analisis data yang digunakan didasarkan pada jawaban siswa pada tes tertulis dan hasil wawancara. Selanjutnya data yang diperoleh akan dianalisis dengan tahapan (1) reduksi data, yakni melakukan proses memeriksa dan menelaah terhadap hasil tes GEFT, hasil tes subjektif, dan hasil wawancara; (2) pemaparan data, yaitu mengklasifikasi dan mengidentifikasi data yang sudah ada untuk disusun secara rapi dan terorganisir; (3) menarik kesimpulan berdasarkan paparan data yang telah dilakukan serta menyesuaikan dengan makna yang terkandung dalam pertanyaan penelitian. 


\title{
HASIL DAN PEMBAHASAN
}

Penelitian bertempat di SD Islam Mohammad Hatta Kota Malang dengan jumlah sampel sebanyak 27 siswa kelas IV C. Kepada seluruh sampel diberikan tes GEFT guna mengetahui jenis gaya kognitif yang dimiliki. Dengan informasi ini, maka peneliti menentukan subjek penelitian sebanyak tiga orang dengan gaya kognitif field dependent untuk diberikan soal pemecahan masalah matematika. Setelah subjek mengerjakan soal, maka langkah selanjutnya yaitu wawancara yang dilakukan langsung oleh peneliti sendiri. Berikut ini bentuk soal yang diberikan pada siswa.

\begin{abstract}
Dalam rangka merayakan ulangtahun yang ke-11, Febby berencana mendekorasi rumah dengan rangkaian balon. Untuk itu maka Febby membeli tiga pack balon dengan warna berbeda yang setiap pak berisi lima balon. Jika setiap rangkaian terdiri dari tiga balon, maka tentukan kemungkinan rangkaian balon yang dapat digambar apabila Febby menginginkan setiap rangkaian terdiri dari minimal dua balon dengan warna yang sama.
\end{abstract}

Hasil pekerjaan yang ditunjukkan oleh subjek berbeda-beda antar satu dengan lainnya. Pada lembar jawaban terlihat bahwa S1 mampu memahami soal dengan cukup baik. Siswa dapat menyebutkan apa yang diketahui, ditanyakan, dan informasi penting lain. Berdasarkan hasil jawaban yang diberikan, terlihat bahwa siswa mampu merencanakan strategi dan menyelesaikan soal sesuai dengan yang telah direncanakan. Tahap pertama S1 menghitung terlebih dahulu jumlah keseluruhan balon yang ada dengan cara mengalikan jumlah balon tiap pak dengan banyak pak balon yang dibeli. Pada langkah kedua, S1 membuat gambar rangkaian balon sesuai dengan syarat yang ditentukan soal yakni minimal rangkaian terdiri dari 2 balon dengan warna yang sama. Adapun gambar rangkaian balon yang dibuat oleh S1 yaitu MMM (merah, merah, kuning), KKH (kuning, kuning, hijau), HHM (hijau, hijau, merah), KKM (kuning, kuning, merah), HHK (hijau, hijau, kuning). Hasil kerja S1 ditunjukkan pada Gambar 1.

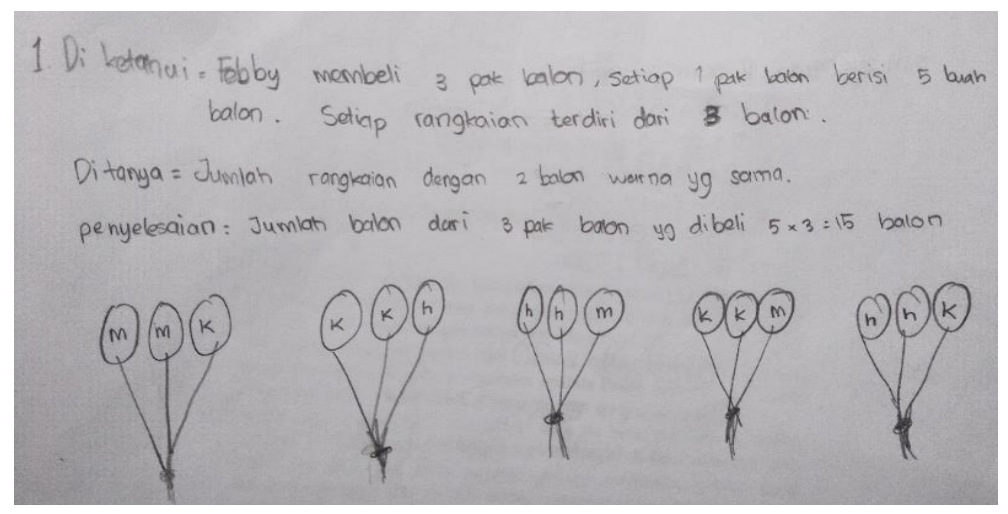

Gambar 1. Hasil Kerja S1

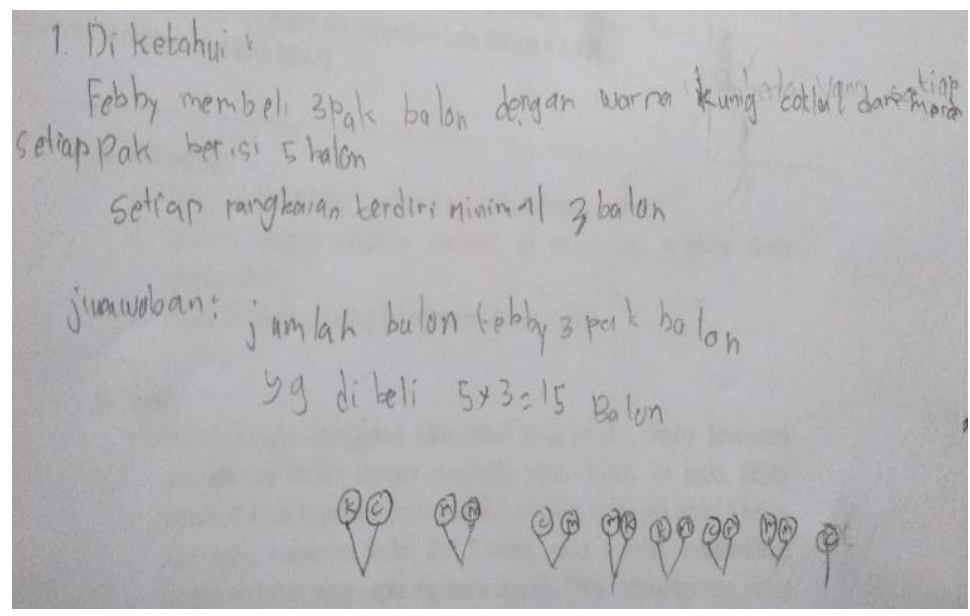

Gambar 2. Hasil Kerja S2 
Pada tahap memeriksa kembali, S1 menyatakan telah melakukan pemeriksaan kembali terhadap langkah-langkah serta jawaban yang diberikan dengan cara melihat kembali rangkaian yang telah digambarkan. S1 melihat simbol-simbol dari huruf pertama warna balon yang digunakan untuk setiap rangkaian agar sesuai dengan syarat soal. Selain itu, S1 juga melihat secara teliti warna untuk keseluruhan rangkaian agar tidak terjadi pengulangan. Akan tetapi, S1 tidak menuliskan kesimpulan diakhir jawaban. Setelah dikonfirmasi ternyata S1 lupa dalam menuliskan kesimpulan.

Berbeda dengan S1, pada tahap memahami masalah terlihat bahwa S2 memiliki pemahaman yang kurang terhadap soal. S2 hanya menuliskan yang diketahui, sedangkan yang ditanyakan dan dipersyaratkan tidak mampu dituliskan. Selain itu, S2 juga tidak dapat menuliskan rencana penyelesaian yang akan dilakukan. Akibatnya S2 melakukan kesalahan pada saat penyelesaian masalah. Berdasarakan Gambar 2, tampak bahwa S2 tidak mampu menggambar rangkaian balon sesuai dengan ketentuan pada soal. S2 hanya menggambar rangkaian balon yang berisi dua buah balon dengan warna berbeda. Pada saat wawancara dilakukan, diperoleh informasi bahwa S2 tidak begitu memahami soal dengan baik dan kurang teliti sehingga tidak mengherankan apabila S2 mengalami kesulitan pada saat menyelesaikan masalah.

Untuk S3, subjek mampu memberikan pemahaman yang cukup baik. S3 mampu menuliskan yang diketahui serta ditanyakan walaupun kurang begitu lengkap. Pada lembar jawaban yang diberikan, diketahui bahwa S3 langsung melakukan penyelesaian tanpa melalui tahap merencanakan. S3 langsung melakukan proses perhitungan dan kemudian menggambar rangkaian balon yang mungkin terbentuk. Adapun gambar rangkaian balon yang dibuat oleh S3 yaitu MMK (merah, merah, kuning), BBK (biru, biru, kuning), BBM (biru, biru, knuning), dan KKM (kuning, kuning, merah). Saat wawacara dilakukan diperoleh informasi bahwa S3 melakukan pemeriksaaan kembali terhadap langkah-langkah penyelesaian yang telah dibuat. Namun, S3 lupa menuliskan kesimpulan di akhir jawaban. Hasil pekerjaan S3 ditunjukkan pada Gambar 3. Berdasarkan hasil penelitian yang telah dikemukakan, maka terdapat beberapa poin terkait proses pemecahan masalah matematika siswa field dependent yang dapat dilihat pada Tabel 1.

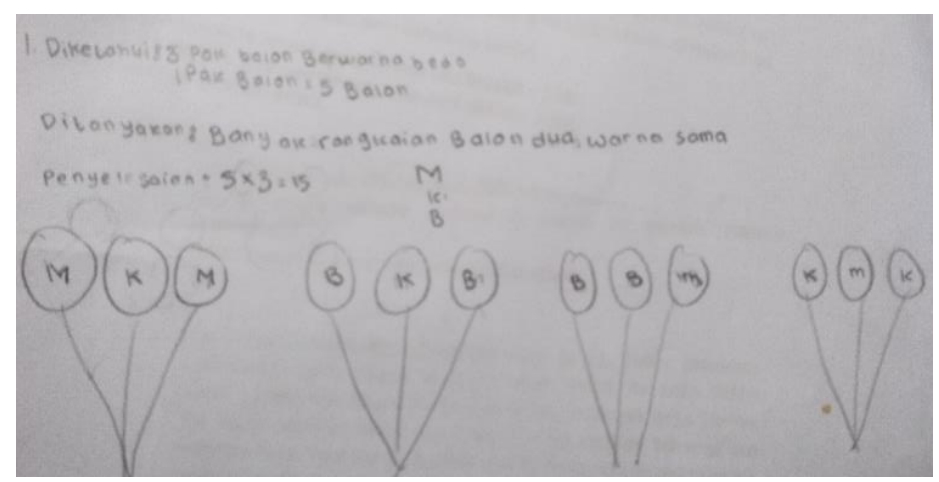

Gambar 3. Hasil Kerja S3

Tabel 1. Aktivitas Pemecahan Masalah Subjek Field Dependent

\begin{tabular}{|c|c|c|c|}
\hline \multirow{2}{*}{$\begin{array}{l}\text { Tahap Pemecahan } \\
\text { Masalah }\end{array}$} & \multicolumn{3}{|c|}{ Indikator Pemecahan Masalah } \\
\hline & S1 & S2 & S3 \\
\hline Memahami Masalah & $\begin{array}{l}\text { Menuliskan yang diketahui dan ditanyakan } \\
\text { secara deskriptif sesuai dengan soal. }\end{array}$ & $\begin{array}{l}\text { Menuliskan yang diketahui } \\
\text { secara deskriptif menggunakan } \\
\text { bahasa sendiri soal meskipun } \\
\text { kurang lengkap }\end{array}$ & $\begin{array}{l}\text { Menuliskan yang diketahui } \\
\text { dan ditanyakan dengan } \\
\text { bahasa sendiri secara poin- } \\
\text { poin. }\end{array}$ \\
\hline $\begin{array}{l}\text { Menentukan Strategi } \\
\text { Penyelesaian }\end{array}$ & $\begin{array}{l}\text { Menentukan strategi penyelesaian yang } \\
\text { akan digunakan secara tulisan dan mampu } \\
\text { menjelaskan secara verbal dan baik }\end{array}$ & $\begin{array}{l}\text { Memikirkan dan menulis } \\
\text { strategi penyelesaian dan } \\
\text { mampu menjelaskan secara } \\
\text { verbal }\end{array}$ & Langsung mengerjakan soal \\
\hline Menyelesaikan Masalah & $\begin{array}{l}\text { Menyelesaikan soal dengan mengacu pada } \\
\text { rencana penyelesaian yang disusun } \\
\text { sebelumnya dan menemukan jawaban } \\
\text { yang diinginkan }\end{array}$ & $\begin{array}{l}\text { Tidak mampu menyelesaikan } \\
\text { soal dengan baik diakibatkan } \\
\text { karena kurangnya pemahaman } \\
\text { terhadap soal. }\end{array}$ & $\begin{array}{l}\text { hingga menemukan } \\
\text { jawaban yang diinginkan. } \\
\text { Mengecek kembali langkah- } \\
\text { langkah penyelesaian. }\end{array}$ \\
\hline Memeriksa Kembali & $\begin{array}{l}\text { Melakukan pemeriksaan kembali terhadap } \\
\text { langkah-langkah secara keseluruhan } \\
\text { penyelesaian yang telah dilalui. }\end{array}$ & & \\
\hline
\end{tabular}


Berdasarkan Tabel 1, subjek dengan gaya kognitif field dependent yaitu S1 cenderung melakukan pemecahan masalah berdasarkan tahapan Polya. Hal ini berbeda dengan dua subjek lainnya yaitu S2 dan S3 yang cenderung melakukan aktivitas pemecahan masalah tidak sesuai tahapan Polya yang seharusnya. Pernyataan ini sejalan dengan Desmita (2009) yaitu siswa field dependent sukar untuk memusatkan situasi atau menganalisa pola yang ada agar menjadi komponen-komponen tertentu. Selain itu, Brown (1983) juga menyatakan individu dengan field dependent lebih berpikir secara global dan dipengaruhi lingkungan sekitar, serta memandang suatu masalah sebagai hal yang membingungkan. Akibatnya terdapat kesalahan pada hasil jawaban subjek.

Hasil dari wawancara yang dilakukan memberikan informasi adanya kesamaan yang dimiliki ketiga subjek yakni kemampuan menjelaskan secara verbal terhadap semua informasi yang ada secara baik namun sulit mengungkapkan dalam bahasa matematika. Temuan ini sejalan dengan Murtafiah (2017) yang mengungkapkan bahwa individu dengan field dependent mampu memahami bahasa verbal, namun kesulitan mengungkapkan dalam kalimat matematika. Selain itu, hasil analisis terhadap ketiga subjek menunjukkan ciri-ciri sebagai individu yang field dependent, yakni memerlukan motivasi dan berpatokan pada isyarat dari luar untuk menyelesaikan masalah (Nisa, Sa'dijah, \& Qohar, 2016). Lebih lanjut, Lusiana (2017) menyatakan bahwa siswa field dependent cenderung memerlukan dorongan dan petunjuk dari guru untuk menyelesaikan masalah, akibatnya siswa menjadi kurang mandiri.

\section{SIMPULAN}

Berdasarkan hasil dan pembahasan mengenai pemecahan masalah matematika pada siswa kelas IV dengan field dependent dalam menyelesaikan masalah matematika, maka dapat disimpulkan beberapa hal sebagai berikut. Pertama, subjek menerima masalah dengan membaca dan memahami maksud soal, mengidentifikasi unsur-unsur penting dalam soal meskipun kurang lengkap. Kedua, subjek S1 cenderung melalui semua tahapan pemecahan Polya dalam menyelesaikan soal, sedangkan subjek S2 dan S3 cenderung melompoti beberapa tahapan pemecahan masalah Polya dalam menyelesaikan masalah. Ketiga, Ketiga subjek S1, S2, dan S3 dapat menjelaskan dengan cukup baik terkait informasi yang diperoleh dan langkah-langkah penyelesaian yang akan dan sedang digunakan sehingga cenderung memiliki kemampuan verbal yang baik.

Adapun saran yang dapat diberikan terkait hasil penelitian ini yakni, dalam pembelajaran matematika hendaknya guru memberikan perhatian khusus kepada siswa yang memiliki gaya kognitif field dependent dengan cara sering menunjukkan langkah-langkah penyelesaian. Selain itu, siswa sebaiknya diberi motivasi untuk dapat mengembangkan kemampuan dalam mengungkapkan kalimat matematika.

\section{DAFTAR RUJUKAN}

Anderson, J. (2009). Mathematics Curriculum Development and the Role of Problem Solving. In ACSA Conference (pp. 1-8).

Brown, E., Brailsford, T., Fisher, T., Moore, C. A., \& Ashman, H. (2006). No TReappraising Cognitive Styles in Adaptive Web Applications. In Proceedings of the 15th International World Wide Web Conference (pp. 327-325).

Brown, F. G. (1983). Principles of Education and Psycological Testing. New York: Holt Rinehart and Winston Inc. Desmita. (2009). Psikologi Perkembangan Peserta Didik. Bandung: PT Remaja Rosdakarya.

Diana, R. F., Irawan, E. B., \& Susiswo. (2017). Proses Koneksi Matematis Siswa Bergaya Kognitif Reflektif dalam Menyelesaikan Masalah Aljabar Berdasarkan Taksonomi Solo. Jurnal Kajian Pembelajaran Matematika, 1(1), $52-63$.

Gordon, H. R. D., \& Wyant, L. J. (1994). Cognitive Style of Selected International and Domestic Graduate Student at Marshall University. Educational Resources Information Center. Huntington, West Virginia.

Lusiana, R. (2017). Analisis Kesalahan Mahasiswa dalam Memecahkan Masalah pada Materi Himpunan Ditinjau dari Gaya Kognitif. JPPM, 1(1), 24-29.

Maimunah., Purwanto., Sa'dijah, C., \& Sisworo. (2016). Penerapan Model Pembelajaran Matematika Melalui Pemecahan Masalah untuk Meningkatkan Penalaran Matematis Siswa Kelas X-A SMA AL-Musilum. Jurnal Review Pembelajaran Matematika, 1(1), 17-30.

Murtafiah. (2017). Deskripsi Kemampuan Pemecahan Masalah Matematika Ditinjau dari Gaya Kognitif Mahasiswa Pendidikan Matematika Universitas Sulawesi Barat. Jurnal Pendidikan MIPA, 7(1), 48-52.

Nisa, H. M., Sa'dijah, C., \& Qohar, A. (2016). Kemampuan Pemecahan Masalah Matematika Siswa SMK Bergaya Kognitif Field Dependen. In Prosiding Seminar Matematika dan Pendidikan Matematika (pp. 230-239).

Polya, G. (1973). How to Solve It. Secon Edition. New Jersey: Princeton University Press.

Salameh, E. M. (2011). A Study of Al Balqa' Applied University Students Cognitive Style. International Education Studies, 4(3), 189-193.

Suherman, E., \& Dkk. (2003). Strategi Pembelajaran Matematika Kontemporer. Bandung: JICA.

Ulya, H. (2016). Profil kemampuan pemecahan masalah siswa bermotivasi belajar tinggi berdasarkan ideal problem solving. Jurnal Konseling Gusjigang, 2(1), 90-96. https://doi.org/10.24176/jkg.v2i1.561

Witkin, H. A. (1971). Group Embedded Figure. California Mind Garden, inc. 
148 Jurnal Pendidikan, Vol. 4, No. 2, Bln Februari, Thn 2019, Hal 143-148

Witkin, H. A., Moore, C. A., Goodenough, D., \& Cox, P. W. (1977). Field-Dependent and Field-Independent Cognitive Styles and Their Educational Implications. Review of Educational Research, 47(1), 1-64. https://doi.org/10.3102/00346543047001001

Zaif, A., Sunardi, \& Diah, N. (2013). Penerapan Pembelajaran Pemecahan Masalah Model Polya untuk Menyelesaikan Soalsoal Pemecahan Masalah pada Siswa Kelas IX SMP Negeri 1 Jember Semester Ganjil Tahun Ajaran 2012/2013. Pancaran, 2(1), 119-132. 